\title{
Skytevåpen og forebygging av selvmord
}

Ved Ingebjørg H estetun

\begin{abstract}
Tiltak som tar sikte på å begrense tilgang på selumordsmetoder, er viktige i det selumordsforebyggende arbeidet. Hensikten med disse tiltakene er å redusere risikoen for at et menneske tar livet sitt. Slike tiltak baserer seg på antakelsen om at a) begrensning i tilgang på en metode fører til at en suicidal person i mindre grad tar metoden i bruk, og b) en får ikke en tilsvarende overgang til andre og like farlige eller farligere selvmordsmetoder. I Norge har vi relativt høy våpentetthet og mange selumord ved bruk av skytevåpen. Begrensning i tilgang på skytevåpen er derfor et naerliggende forebyggende tiltak. Her vil jeg gå gjennom forskning som dreier seg om sammenhengen mellom tilgang på skytevåpen og selumord, og vise til noen aktuelle tiltak.
\end{abstract}

\section{Selvmord og tilgang på metode}

Det er stor enighet om at begrensning av tilgang på en selvmordsmetode reduserer antall selvmord når metoden har høy dødsrisiko og er mye brukt. Som eksempel vises det ofte til avgiftning av kullgass $i$ England. Slik gass brukesi husholdningen og er derfor lett tilgjengelig. 0 ver ei 20 årsperiode blei karbonmonoksid fjernet fra gassen slik at den blei mindre farlig. Parallelt med dette skjedde det en nedgang i antall selvmord ved bruk av slik gass, uten en tilsvarende økning i selvmord ved bruk av andre metoder (Kreitman 1976). I denne type forskning er en oppmerksom på muligheten av metodesubstitusjon, det vil si om vi finner en overgang til andre og like farlige metoder. G enerelt kan en si at selv om slik overgang i noen grad finner sted, finner en ofte en nedgang $i$ antall selvmord som resul tat av at en metode blir vanskeligere tilgjengelig, som i det nevnte eksemplet fra England.

\section{Skytevåpen og selvmord}

En rekke undersøkelser fra U SA viser en overhyppighet av selvmord i familier som har våpen i heimen. Etter en gjennomgang av forskning som tar opp sammenheng mellom tilgang på våpen og selvmord konkluderer $\mathrm{M}$ iller og $\mathrm{H}$ emenway (1999) med at våpentilgjengelighet er en risikofaktor for sel vmord blant ungdom i U SA . D et ser også ut til at våpentilgjengelighet øker risiko for selvmord blant voksne, selv om en slik sammenheng ikke er like tydelig. I en seinere undersøkelse der en så på våpentetthet og sel vmordsrater i U SA , fant Birckmayer \& H emenway (2001) en slik sammenheng blant de yngste, det vil si i aldersgruppa 15-24 år, og blant de eldste, i aldersgruppa 65-84 år. Videre beregnet forskerne at dersom denne sammen hengen er kausal, kunne en $10 \%$ nedgang i våpentetthet resultere i en $3 \%$ nedgang i selvmordsrater. I en undersøkel se fra Finland viser forskerne til at tilstedeværelsen av jaktvåpen i heimen innebærer lett tilgang til en metode med høy risiko for død, og finner sammenheng mellom dette og høy selvmordsrate blant menn i aldersgruppa 15-24 år (H intikka 1997). Verdens helseorganisasjon har satt opp begrensninger i tilgang på skytevåpen som et av de viktigste virkemidlene for å redusere antall selvmord.

\section{Hvorfor er sikker oppbevaring av skytevåpen livsviktig?}

$M$ ange selvmord skjer som resultat av ei impulshandling, i forbindelse med ei alvorlig, men midlertidig krise, der vedkommende har opplevd sterk ambivalens i forhold til å ta livet sitt. Dette blir støttet i undersøkelser av personer som har overlevd alvorlig skuddskade etter å ha forsøkt å ta livet sitt ved skyting (Peterson et al 1985, Chapdelaine et al 1991). Dersom selvmordsmetoden - bruk av våpen - blir vanskeligere tilgjengelig, kan en derfor redusere antall selvmord som skjer $\mathrm{i}$ affekt. $\mathrm{N}$ å kan en innvende at andre metoder også er lett tilgjengelige. D et ser imidlertid ut til at en person ikke uten videre vil ta i bruk en alternativ metode. Dersom et våpen er forskriftsmessig nedlåst, blir det vanskeligere for andre, $f$. eks en ungdom i huset, å få tak $\mathrm{i}$ våpenet. $0 \mathrm{gså} \mathrm{for} \mathrm{våpeneieren}$ kan ei slik nedlåsing gi en livreddende forsinkelse. $N$ år en person i selvmordskrise må bruke tid og foreta en serie handlinger for å gjøre klart et våpen, øker sannsynligheten for at han eller hun får tenkt seg om, ombestemmer seg og skaffer seg hjelp. Sikker oppbevaring av skytevåpen er derfor viktig ikke bare for å hindre tjuveri eller at barn uforvarende skal komme over skytevåpen et, men også som et forebyggende tiltak mot selvmord.

I mange forskningsprosjekter har en sett på våpentetthet og selvmord. I mindre grad har en studert betydningen av hvorledes våpen blir oppbevart. Selv om en ikke kan trekke sikre konklusjoner, ser det ut som om sikker oppbevaring av våpen reduserer risiko for selvmord spesielt når det gjelder yngre mennesker ( $M$ iller \& Hemenway 1999).

\section{Våpenlovgivning og selvmord}

Etter å ha gjennomgått forskning på sammenhengen mellom lovverk og selvmord konkluderer Lambert og Silva (1998) med at selvmordsraten typisk går ned etter innføring av strengere våpenlover. 0 vergang til andre metoder finner sted $\mathrm{i}$ begrensa omfang. D ette er også konklusjonen $i$ en nyere undersøkelse fra U SA (C onner $\&$ Zhong 2003),

I USA, der mye av forskningen er utført, er andelen av håndvåpen større enn f. eks i N orge. C anada har som N orge tradisjon for jakt kombinert med begrensninger i våpenhold. En undersøkelse fra 0 ntario i C anada er derfor spesielt interessant.

Canada fikk i 1978 strengere lovgivning når det gjelder våpenhold. Samtidig blei det iverksatt en opplysningskampanje om betydningen av sikker bruk og oppbevaring av văpen. I første omgang fant en ikke at dette førte til redusert forekomst av selvmord. G jennom detaljert analyse der forskerne blant anna korrigerte for endring $i$ alderssammensetning $i$ befolkningen, kunne imidlertid $C$ arrington og M oyer (1994) vise en nedgang i selvmordsraten som var relatert til færre våpenselvmord. En kan ikke fastslå med sikkerhet at strengere lovgivning er årsak til disse endringene. $M$ en en fant et markert fall i antall selvmord ved skyting i den første tiden etter at en fikk de strengere lovene, uten at dette kunne relateres til en overgang til andre metoder. Dette er en klar indikasjon på at den strengere lovgivningen førte til færre selvmord. Etter en gjennomgang av flere studier som tar opp be- 
tydningen av strengere våpenlov i C anada konkluderer også Leenaars og medarbeidere (2003) med at innføringen av den strengere lovgi vningen ser ut til å redusere risiko for selvmord.

U ndersøkelser fra A ustralia (Snowdon \& H arris 1992, Cantor \& Slater 1995) er mindre grundige, men støtter funnene fra $C$ anada. $N$ å har en i A ustralia sett en økning i bruk av hengning som tilsynelatende er parallell med reduksjon i bruk av skytevåpen. N ærmere analyse viste imidlertid at dette ikke kan forklaresmed metodesubstitusjon: overgang fra skyting til hengning. $\varnothing$ kning i antall selvmord ved hengning fant $f$. eks. sted før reduksjon i skyteselvmord. (De Leo 2003). Selv om vi òg finner undersøkelser som ikke viser slik sammenheng mellom lovverk og selvmord, anbefaler Lester (1998), etter en gjennomgang av denne forskningen, strenge våpenlover som et selvmordsforebyggende tiltak.

\section{Skytevåpen i Norge}

N orge har mange våpen i privat eie. Pr. 01.03.2004 er det registrert 1.159.154 våpen i det sentrale våpen registret ( $\mathrm{A}$ asberg 2004). I tillegg kommer lovlige ikkeregistrerte hagler (hagler ervervet før 1990) og $\mathrm{H}$ eimevernets utplasserte våpen. U tbredelsen av våpen i privat eie i N orge er derfor ikke så langt fra hva en finner i USA. Der vises det ofte til den enkeltes behov for beskyttelse som begrunnelse for å ha skytevåpen, og håndvåpen er vanlig. Til forskjell fra U SA er våpen i N orge oftere knyttet til jakt. I 2003 var det registrert 371.173 jegere i landet vårt (Statistisk sentral byrå 2004a). Skyting som idrettsaktivitet er også viktig, og vi har tradisjonelt sett oppfattet våpen i befolkningen som ledd i vårt forsvar av landet. Bruk av skytevåpen er en av de vanligste selvmordsmetodene. I 2002 blei det registrert 90 selvmord ved skyting, 87 menn og 3 kvinner. Dette er ca. 1/4 av alle selvmord blant menn. Totalt blei det registrert 362 selvmord blant menn og 132 blant kvinner dette året. Få kvinner tar livet sitt med skytevåpen. Selvmord ved skyting har gått ned de seinere årene, både i antall og som andel av det totale antallet selvmord. Høyest antall registrerte selvmord ved skyting finner vi i perioden 1986-90. Da tok 176 menn livet sitt med skytevåpen i gjennomsnitt pr. år. Det totale antall selvmord blant menn var 477 i gjennomsnitt pr. år. (Statistisk sentralbyrå 2004b)

\section{Regler for jakt og våpenhold i Norge}

Vi har strenge regler for hvorledes våpen skal oppbevares i heimen. I følge $V$ åpenloven (2001: §27a) skal eiere av skytevåpen, våpendeler eller ammunisjon oppbevare gjenstandene slik at uvedkommende ikke făr adgang til dem, det vil si forsvarlig nedlåst. V åpenforskriften (2003: kap. 22) gir detaljerte bestemmelser om dette, og sier blant anna at innehavere av håndvåpen og flere enn fire registreringspliktige rifler eller hagler må oppbevare våpnene eller vitale deler i et godkjent sikkerhetsskap. V åpen i H eimevernet sikres gjennom innlevering av tennstempler, og en har planlagt innføring av kammerlås. A I dersgrensene for å erverve seg våpen er 18 år for rifler og hagler, og 21 år for håndvåpen (revolver/pistol). For å drive jakt på småvilt må jegeren være fylt 16 år, aldersgren sa for storvilt er 18 år. N ye jegere skal gå gjennom en 30-timers opplæring som omfatter blant anna forsvarlig våpenbruk, og de må ha bestått jegerprøven. Etter nærmere an gitte regler kan også yngre delta i jakt, som ledd i opplæring.

I 2003 fikk vi etablert et sentralt våpenregister, som gjør det mulig raskt å finne ut om det er registrert skytevåpen på en person og ei adresse. Fra september 2003 og ett år framover har vi også fått et våpenamnesti, som innebærer at personer som har ulovlige og uregistrerte våpen kan innlevere disse til politiet uten å risikere straffeforfølging, og eventuelt søke om å beholde våpenet dersom det brukes til for eksempel jakt. I løpet av de første 4 månedene av amnestiet blei over 2500 våpen innlevert ( $A$ asberg 2004).

\section{Tiltak}

I N orge har vi lang tradisjon for å drive med jakt, og skytevåpen er i stor grad knytta til jakta. D et er derfor ikke realistisk å redusere antall jaktvåpen i betydelig grad. D ette blir heller ikke oppfatta som ønskelig på grunn av den betydningen som jakt har i vår forvaltning av naturen og som glede og rekreasjon for jegerne. Det blir likevel viktig å finne fram til tiltak som kan redusere antall selvmord med

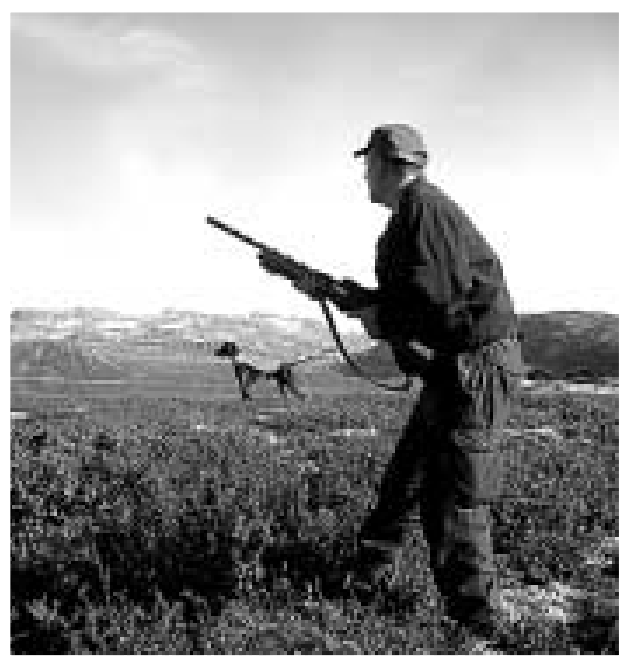

skytevåpen uten at vi mister mulighetene til å drive jakt eller sportslige aktiviteter som involverer skytevåpen. Forsvarlig oppbevaring og nedlåsing av våpen er et slikt tiltak.

Ved Seksjon for selvmordsforskning og -forebygging ville vi engasjere oss i forebygging av selvmord med skytevåpen, men vi var usikre på hvilke konkrete tiltak som kunne være aktuelle. Vi tok derfor kontakt med miljøer som arbeider med jakt og våpen, slik at vi sammen kunne drøfte hva som kunne gjøres; blant anna $\mathrm{N}$ orges jeger- og fiskerforbund, N orges skytterforbund, D et frivillige skyttervesen, J ustis- og politidepartementet, Politidirektoratet og Direktoratet for naturforvaltning. I disse miljøene var en i utgangspunktet mindre oppmerksom på sammenhengen mellom selvmord og skytevåpen, men oppfattet umiddel bart problemstillingen som viktig og blei opptatt av à inn gå samarbeid om konstruktive tiltak.

H ovedfokus i det samarbei det som er startet opp, har vært å nå fram med informasjon om betydningen av våpensikring til jegere og andre vâpeneiere, samt å få problemstillingen inn i forbindelse med opplæring av nye jegere. En tenker seg at når våpeneiere får forståel se for hvor viktig det er å sikre våpen, vil den enkelte også bli mer påpasselig med hvorledes skytevåpen oppbevares.

\section{Pasienter som innehar våpen}

I hel sevesenet har en ikke vært tilstrekkelig oppmerksom på sammenheng mellom tilgang på skytevåpen og sel vmord. $\mathrm{H}$ elsepersonell er ei viktig målgruppe for slik informasjon. H vor vanlig er det f. eks. at en behandler som møter en person i 
krise og er bekymra for selvmordsfare, spør om vedkommende har slike våpen? Dersom en får kjennskap til at pasienten har våpen, må en drøfte hvorledes disse kan sikres. Våpen kan alltid innleveres til politiet. Vi kjenner flere eksempler på våpeneiere som i ei følelsesmessig krise selv ber om at politiet oppbevarer skytevåpen ei periode (Hynne 2004). Terskelen for å gjøre dette kan være høyere for noen fordi en ikke veit hva som skal til for å få våpen tilbake når en kjenner seg psykisk stabil. Usikkerhet om dette kan en også ta opp med politiet.

Helsepersonell har taushetsplikt om pasientforhold. Dette er n $\varnothing$ dvendig for tillitsforholdet mellom pasient og behandler. Men en pasient kan gi samtykke til at opplysninger gis til andre, slik at en kan få sikret skytevåpen. Det finnes situasjoner der en ikke får slikt samtykke. Derfor er det gitt unntak fra taushetsplikten når det er nødvendig å gi informasjon videre av hensyn til pasientens eller andres sikkerhet. Sosial- og helsedirektoratet sendte i 2003 ut et rundskriv til helsepersonell, der en tar opp forholdet mellom taushetsplikt og rett og/eller plikt til å gi informasjon til politi og militære myndigheter når psykisk ustabile personer er $\mathrm{i}$ besittelse av våpen og dette utgjør en alvorlig risiko for personen selv eller andre (Sosial- og helsedirektoratet 2003).

Våpen som oppbevares i heimen, kan også representere en fare for andre. Det finnes altfor mange eksempler på at en ungdom har tatt livet sitt med et usikra våpen som tilhører en annen person i husstanden. Når en som behandler eller i annen sammenheng får kjennskap til at et ungt menneske sliter med selvmordsimpulser, er det derfor viktig å spørre foreldrene om det er våpen i heimen, og om disse eventuelt er forsvarlig nedlåst.

Det finnes lite forskning som tar opp betydningen av å gi slik informasjon til våpeneiere. I to mindre unders $\varnothing$ kelser tok en opp i hvilken grad foreldre til ungdom med psykiske vansker fulgte råd om oppbevaring eller fjerning av våpen eller medikamenter. Foreldre til ungdom som blei brakt til sykehus som $\varnothing$ yeblikkelig hjelp for vurdering på grunn av psykisk krise, fikk undervisning om betydningen av å sikre eller fjerne våpen og medika- menter. Dette blei gjort med henvisning til faren for selvmord. Foreldrene som fikk slik undervisning, satte i verk tiltak

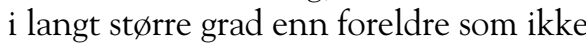
fikk slik opplysning (Kruesi et al 1999). Derimot fant Brent og medarbeidere (2000) at foreldre til deprimerte ungdommer ofte ikke fulgte råd om å fjerne skytevåpen fra heimen, til tross for klare råd om dette og med henvisning til suicidalfare. I denne unders $\varnothing$ kelsen registrerte en ikke nedlåsing av våpen som et adekvat tiltak. Vi trenger mer kunnskap både om hva som skal til for at våpeneiere skal følge råd som gis, og om hvilken betydning for eksempel oppbevaring av våpen har for reduksjon i antall selvmord.

\section{Konklusjon}

Forskning viser at det er en sammenheng mellom selvmord og våpentetthet. Verdens helseorganisasjon har satt opp begrensninger $\mathrm{i}$ våpentilgang som et av de viktigste virkemidlene for å redusere antall selvmord. I Norge må sikrere oppbevaring av våpen i heimen bli sett på som et viktig virkemiddel for å begrense våpentilgang og redusere antall selvmord. Dette bør være en naturlig del av god norsk jakt- og idrettskultur - en kultur som vi фnsker å ta vare på.

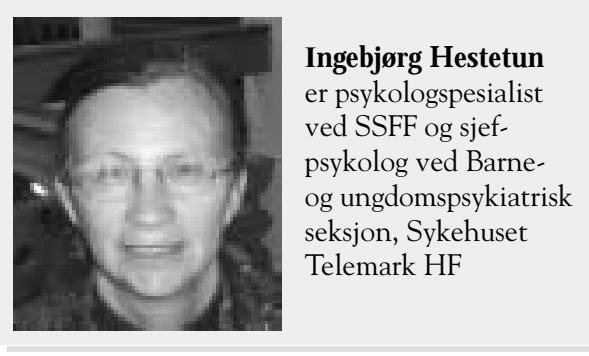

\section{Referanser}

Brent DA, Baugher MA, Birmaher B, Kolko DJ, Bridge J. Compliance with recommendations to remove firearms in families participating in a clinical trial for adolescent depression. Journal of the American Academy of Child \& Adolescent Psychiatry 2000; 39: 1220-1225

Birckmayer J, Hemenway D: Suicide and firearm prevalence: A re youth disproportionately affected? Suicide and Life-Threatening Behavior 2001; 31: 303-310

Cantor CH, Slater PJ. The impact of firearm control legislation on suicide in Q ueensland: Preliminary findings. Medical Journal of Australia 1995; 162: 583-585

Carrington PJ, Moyer S: G un control and suicide in O ntario. American Journal of Psychiatry 1994; 151: 606-608
Chapdelaine A, Samson E, Kimberly MD. Firearm related injuries in C anada. Issues for prevention. Canadian Medical Association Journal 1991; 145: 1217-1223

Conner KR, Zhong Y. State firearm laws and rates of suicide in men and women. American Journal of Preventive Medicine 2003; 25: 320-324

De Leo D, Dwyer J, Firman D, Neulinger K. Trends in hanging and firearm suicide rates in $A$ ustralia: Substitution of method? Suicide and Life-Threatening Behavior 2003; 33: 151-164

Hintikka J, Lehtonen J, Viinamaki H. H unting guns in homes and suicides in 15-24-year-old males in eastern Finland. Australian and New Zealand Journal of Psychiatry 1997; 31: 858-61

Hynne S. Skien politistasjon, personlig meddelelse 17.03.04

Kreitman N. T he coal gas story. British Journal of Preventive and Social medicine 1976; 30: 86-93

Kruesi MJP, Grossman J, Pennington JM, Woodward PJ, Duda D, Hirsch JG: Suicide and violence prevention: Parent education in the emergency department. Journal of the American Academy of Child \& Adolescent Psychiatry 1999; 38:250. 255

Lambert MT, Silva PS. A $\mathbf{n}$ update on the impact of gun control legislation on suicide. Psychiatric Quarterly 1998; 69(2): 127-34

Leenaars AA, Moksony F, Lester D, Wenck-

stern S. T he impact of gun control ( $B$ ill C -51)

on suicide in C anada. Death Studies 2003; 27(2): 103-24

Lester D. Preventing suicide by restricting access to methods for suicide. Archives of Suicide Research 1998; 4: 7-24

Miller M, Hemenway D. T he relationship between firearms and suicide: $A$ review of the literature Aggression and Violent Behavior 1999; 4: 59-75

Peterson LG, Peterson M, O'Shanick GJ, Swann A. Self-inflicted gunshot wounds: Lethality of method versus intent. American Journal of Psychiatry 1985; 142: 228-231

Snowdon J, Harris L. Firearm suicides in A ustralia. Medical Journal of Australia 1992; 152: 79-83

Sosial- og helsedirektoratet: H elsepersonells rett og/eller plikt til å gi informasjon til politi og militære myndigheter om pasienters helsetilstand. Rundskriv IS-7/2003, datert 28.05.2003

www.shdir.no/index.db2?id=5083

Statistisk sentralbyrå (2004a): D ødsårsaker 2002. www.ssb.no/dodsarsak/ 27.2.04

Statistisk sentralbyrå (2004b): Jegerregisteret, 2002/2003: tabell 6: Personer oppført i Jegerregisteret. www.ssb.no/emner/10/04/10/ jegerreg/tab-2003-04-03-06.html 4.2.04

$V$ åpenloven. Lov om skytevåpen og ammunisjon m.v. Oslo: Justisdepartementet, 1961. Sist endret 2001.

V åpenforskriften. Forskrift om skytevåpen, våpendeler og ammunisjon. Oslo: Justisdepartementet, 1963. Siset endret 2003.

Aasberg L. Oslo politidistrikt, Våpenkontoret, personlig meddelelse 11.3.04 